\title{
The NMET impact on the English writing of mainland Chinese students
}

\author{
Linda Lin \\ The Hong Kong Polytechnic University; eclindal@polyu.edu.hk
}

\begin{abstract}
This paper examines the impact of the writing component in the NMET (National Matriculation English Test) on the development of learners' writing skills in China. By analysing the results of three types of data, a writing test (WT) taken by 83 participants who received considerably high scores on the NMET, a questionnaire survey and three focus-group interviews, the study finds the NMET has had a major negative impact on the writing of this group of learners. Factors attributed to this impact include the test design, and the implicit and explicit marking criteria of the NMET.
\end{abstract}

Keywords: NMET, writing skills, assessments, negative impact, English learning in China

\section{Introduction}

China possibly has the largest English-learning population in the world (Zhao 2016). Learning English for most of these learners, however, is to a large extent instrumentally motivated (Cheng 2008). The primary motivation for most learners is to pass various English examinations, in particular, the highstakes tests that can determine their future (Cheng 2008, Fox \& Curtis 2010). Of these tests, the NMET is the most influential one since it has been playing the role of "a traffic wand" in China ever since it was introduced in 1985 (Cheng \& Qi 2006: 64). This is to say that the regimes of the NMET define the national curricula that are designed for the English subjects and the approaches to teaching that teachers adopt in the classroom (Gu 2014, Qian \& Cumming 2017, Zhao 2016). Although a number of local examination authorities have developed their own municipal Matriculation English Test (MET), most METs are merely imitations of the NMET because they follow "the same testing syllabus" and adopt "similar test formats" (Xu \& Wu 2012: 175).

The NMET is the test of candidates' English proficiency in the university entrance test battery in China. Together with the tests in Chinese and Mathematics, it is one of the three compulsory tests for all candidates and is thus crucial in university admission decisions. The main objective of the NMET is to test candidates' ability in reading and their knowledge of English grammar and vocabulary (Hu 2003, You 2010). Little importance is attached to productive skills. This is evident in how the assessment of the two productive language skills is implemented in the NMET. Speaking is absent, i.e. this skill is not tested (except for English majors). Writing is tested, but according to studies (e.g. Qi 2007, Xie 2015, You 2010), the writing component cannot objectively measure the writing skills of candidates. This problem is mainly attributed to the task requirements and the adopted assessment criteria of the NMET.

\section{Task requirements}

The test requires that candidates write a short text around 100 words in the form of guided writing, for example, a description of a place/person, a letter/email, or a composition on a social issue. The task prompt is in Chinese. It lists all the main points that candidates should cover. The points are often listed according to the sequence in which they should appear in the text, which means candidates only need very little effort to organise the text. With most of the content and organisation provided, the test has by and large turned writing into translation (Wu 2008, You 2010). This can be seen from the task prompt for the writing component of the 2017 NMET paper (Paper II).

Figure 1: A translated writing prompt from the 2017 NMET paper.

National Matriculation English Test (Paper II)

2017

Part IV. Writing (*25 marks)

You are Li Hua, who is teaching your British friend, Leslie, Chinese. You need to write an email to Leslie about your next lesson. Your email should include the following points: 


\section{1. time and venue of the lesson;}

2. content to be covered in the lesson: Tang dynasty poetry;

3. preparation required of Leslie for the lesson: gaining a brief understanding of the Tang dynasty history.

Please note that

1. Your email should be around 100 words in length.

2. You can add details to enhance the cohesion and coherence of your email.

\section{Adopted assessment criteria}

It seems that there exist two sets of marking criteria in the scoring process of the NMET, the de jure criteria, the intended ones by the test developers, and the de facto criteria, the enacted ones by many of the NMET raters. According to the official NMET writing construct, the "main idea, coherence, grammar and vocabulary, writing purpose, authorship and readership" should be raters' foci in marking (Mei \& Cheng 2014: 180). However, studies indicate that most raters regard candidates' discrete-point knowledge of English grammar and vocabulary as the core assessment criterion (Hu 2003, Qi 2007). This requirement may not be explicitly written into the official assessment criteria, but in practice, language accuracy plays a crucial role in deciding on scores for the candidates. You (2004: 104) contends that this practice prioritises the "correct form", the discrete-point knowledge of English grammar, rather than the "well-developed thought", the communicative function of writing. The judgment of language-use has also extended to that of candidates' ability to use complex sentence structures and sentence connectors. This is evidenced in Wang's (2013) NMET preparation book, one of the most popular books used by NMET candidates. This book particularly lists the official band-descriptors for Band 5 , the highest band for compositions on the NMET. The purpose is to help candidates understand the factors contributing to top-grade essays. There are four criteria on this band, which are in Chinese. They were translated into English by the author of this article:

1. Addresses all the main points of the task;

2. Uses a relatively wider range of sentence structures and vocabulary;

3. May contain errors in grammar and vocabulary but the errors are caused by candidates' effort in using complex sentences and advanced/infrequent lexis;

4. Effectively uses sentence connectors.

Of these four marking criteria, two directly address the issue of sentence structures and vocabulary (Points 2 and 3). Point 2 is straightforward and easy to understand. However, few students may understand Point 3 due to the implicit message it contains. Wang's book particularly interpreted this point for the purpose of drawing readers' attention to the importance of using complex sentence structures and advanced lexis on the NMET (pp. 17-18). This specification highlighted the importance of complex sentence structures and low-frequency words for achieving a top grade on the NMET:

This is to say, candidates who merely use simple words and sentence structures cannot demonstrate their language abilities, and therefore are less likely to attain high scores even if their compositions are error-free. On the contrary, those who purposely deploy complex sentence structures and advanced lexis are considered stronger candidates with a higher command of the English language. These candidates will be rewarded with high scores on the NMET.

*Translated by the author. Original text in Chinese (see Note 1)

The assessment of sentence structures and vocabulary has also extended to the use of set-phrases, idioms, proverbs and clichés known as "shining phrases" and frequently used phrases or sentence structures in the academic writing of native speakers of English, which are known as "beautiful structures". These "shining phrases" and "beautiful structures" are therefore highly recommended to the NMET candidates by teachers and authors of NMET preparation books.

It is also worth noting that the focus of Point 4 is on cohesion and coherence. However, instead of emphasising the need to deploy a variety of cohesion and coherence devices, this point highlighted the use of sentence connectors. This could be misinterpreted by many NMET candidates that inserting sentence connectors in a text is the most effective way to achieve cohesion and coherence in writing. 
Candidates' ability to maintain a desirable appearance of their writing scripts, which includes clear and neat handwriting, is also assessed (Paltridge 2007, Qi 2007). This requirement, an unwritten rule though it may be, is a critical factor for deciding on candidates' scores. It is so important that some researchers (e.g Wu 2008, Xie 2015) maintain that clear and neat handwriting is one of the four key de facto assessment criteria for the writing component of the NMET (the other three being writing to a word limit, inclusion of main points required by the task prompt and language accuracy).

These task requirements and, to a larger extent, the assessment criteria, either explicitly or implicitly stated, have resulted in negative impacts on the learning, teaching and assessment of writing in China (Cheng 2008, Cheng \& Qi 2006, Qi 2007). The most salient impact is possibly on students' perception of what counts as good writing. Since long and difficult sentences/lexis, beautiful structures/shining phrases, and a large number of sentence connectors are much valued by many NMET raters, some teachers believe texts with these features are closely related to high-quality writing. They therefore provide extensive training for students to include such items in their writing. One of the approaches to such training is to provide NMET exemplary texts and essay templates for students to memorise. Other writing skills, for example, logical development of arguments, cohesion and coherence, and appropriatness of content in terms of the communicative context required by the task, are virtually ignored (Qi 2004). This misplaced focus in teaching, together with many teachers' own limited knowledge and experience in English writing (Jin \& Cortazzi 2006), might cause students to misunderstand what good writing should be like.

Another major impact of the task requirements and the adopted assessment criteria for the writing component is the reliability of the NMET scores. Students' misconception of what count as good writing, and particularly the prevalence of memorising NMET exemplary texts and essay templates have triggered "polluted scores" in the high stakes English tests in the country (Cheng \& Curtis 2010: 270). If a candidate happens to have memorised an essay similar to the topic in the writing task, s/he can slightly modify the essay or simply copy the essay onto the answer sheet. Those who unfortunately have not memorised the right essay are encouraged to integrate "relevant chunks from the samples" into their own writing (You 2010: 154). Since exemplary texts and essay templates are instrumental for the NMET, many candidates concentrate on skills to cope with the writing requirements of the test, but their writing skills are not much improved thereby (Wu 2008, You 2010). This partially explains why Qi (2007) believes the writing section in the NMET cannot objectively gauge the writing skills of the candidates.

Although Qi's view has been shared by many students, teachers and researchers alike (e.g. Song 2016, Xie 2015, Zhao 2016), limited empirical data can be found about the impacts of the NMET on the writing skills of these learners. This study attempts to address this issue by examining the writing skills of a group of students at a university in Hong Kong. All these students completed their secondary school education in mainland China.

\section{Methodology}

Both quantitative and qualitative data were gathered for the current study. The main instrument was a writing test (WT). A questionnaire survey and three focus-group interviews were also conducted to explore participants' English writing experience during their secondary school studies, the strategies they used to manage the writing component in the NMET and the challenges they encountered in the university because of their background of learning English in China.

\section{Participants}

A total of 83 first-year undergraduate students in a university in Hong Kong were invited to participate in the study (35 males and 48 females with an age range of 16 to 22). These students were all from mainland China. As English is used as the medium of instruction in the university, candidates from mainland China must meet the English proficiency requirement by scoring an overall mark of 120 out of 150 on the NMET. This means all the 83 participants attained considerably high scores on the NMET (ranging from 120 to 141 ). 


\section{Test administration}

To minimise the possible impact of a change of language environment on the participants, the WT and the questionnaire survey were administrated in the second week of the new academic year, i.e. two to three weeks after these students entered Hong Kong. The three focus-group interviews were conducted at the end of the semester so that students would fully understand the challenges they faced when functioning in academic contexts by the time they were interviewed. To further control external variables, the participants were also asked to declare in their consent form for the study if they had received additional English support (e.g. receiving private tutoring) after being enrolled into the university. The information gathered indicated that no student had received such help.

The WT was designed to examine the participants' writing skills. It required that all subjects write a 500-word expository essay; and it was administered under controlled conditions regarding time, venue and accessibility to dictionaries and electronic devices. To maximise participants' opportunity to write on topics they are familiar with and comfortable to write about, a pool of nine topics was provided for them to choose from. Here is an example of the nine topics:

Increasing concerns have been expressed in Hong Kong and mainland China about youngsters starting to experience sex at an early age, some even before they are ten years old. Discuss the causes of this problem and suggest ways to deal with it.

\section{Essay scoring}

Two experienced language instructors rated each essay and the 9-scale band descriptors (Task 2) for IELTS (International English Language Testing system) were deployed for the rating. These descriptors have undergone careful research and piloting for their reliability and predictive validity (Shaw \& Falvey 2008, Shaw \& Weir 2007). To further improve the inter-rater reliability in the rating process, the study adopted a two-stage scoring procedure, first holistic scoring and then analytical scoring for scripts that received markedly different scores from the two raters (i.e. different by two scales or above). These measurers ensured the essay scores awarded by the two markers agree strongly with each other (see Table 1). The high reliability of scores provides a firm foundation for analysis for the study.

Table 1: Correlation between two essay-markers.

\begin{tabular}{|c|c|}
\hline & Intra-class correlation coefficients \\
\hline Before adjustment & $.75^{* *}$ \\
\hline After adjustment & $.93^{* *}$ \\
\hline${ }^{* *}$ Significant at .01
\end{tabular}

\section{Questionnaire survey and focus-group interviews}

A questionnaire survey was administered to all the 83 participants after the writing test. The questionnaire, which contained a total of 15 multiple-choice questions in English, was designed mainly to elicit subjects' strategies for coping with writing tasks in English, which they learnt before entering university. As a follow-up measure, three focus-group interviews were also conducted. A total of 35 discussants attended the interviews.

\section{Findings and discussion}

\section{Writing skills of mainland students}

The results of the WT showed that, on average, the writing proficiency of this group of students was considerably low. This is evidenced by the mean score that the 83 essays received, which was 4.11 (the maximum possible grade was 9 , see Table 2 ). Although one student managed to attain 7 on the test, the low standard deviation (SD) of the participants' scores (1.32) indicates that this student was a rather special case and most students in the group received low scores and very few performed satisfactorily.

Table 2: Participants' performance on WT.

\begin{tabular}{|c|c|c|c|c|}
\hline \multirow{2}{*}{$\begin{array}{c}\text { Essay } \\
\text { Grades }\end{array}$} & Min & Max* & Mean & SD \\
\cline { 2 - 5 } & 1 & 7 & 4.11 & 1.32 \\
\hline
\end{tabular}


Figure 2 presents detailed information about the writing performance of these learners. The large majority of them received 4 or 5 on the IELTS 9-scale band (32.5\% and $25.3 \%$ respectively). The scores for almost $15 \%$ of them were 2 or below, which are exceptionally low scores. This result stands in marked contrast to the high scores these participants received on their NMET. When converted according to the 9-band scale used in the IELTS marking scheme, the NMET scores of an overwhelming majority of them fell between 8 and 9 ( $48 \%$ and $47 \%$ respectively), which are remarkably high.

Figure 2: WT and NMET scores according to IELTS 9-scale band.

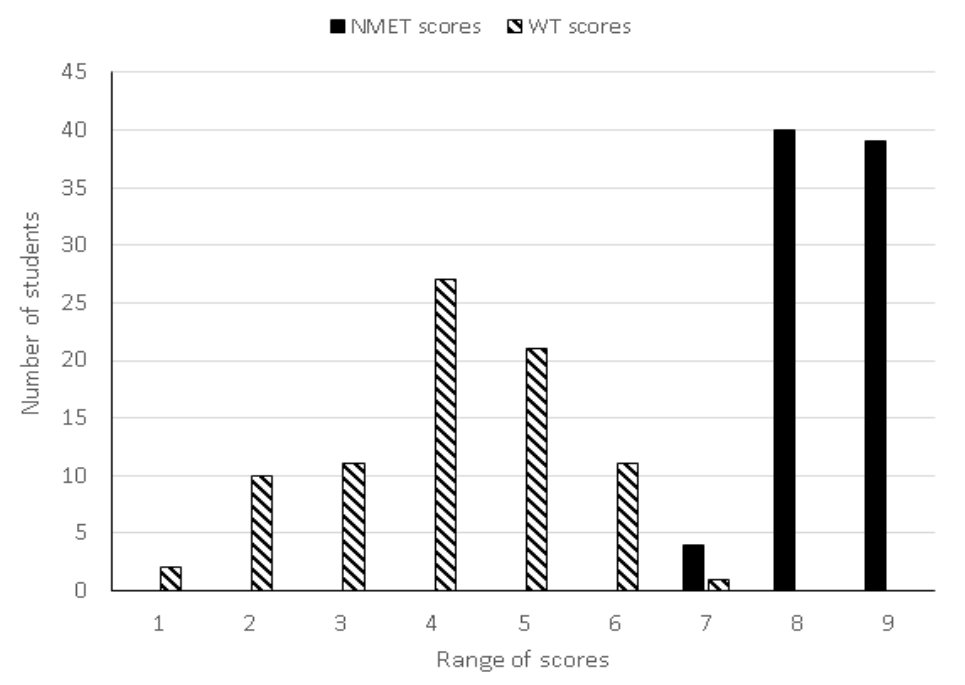

This contrast is not surprising when considering these students' limited writing practice in secondary schools. This limitation is evidenced by the survey questionnaire data of the present study. When asked about experiences in writing, a considerable percentage of the participants (34\%) reported they had very limited experience in this skill (see Table 3). Most respondents who had some training in writing (52\%) did not start practicing writing until they had to prepare for the NMET which according to the focus group interview, was normally in the last semester of secondary school studies. Many of those who had some experience (31\%) only practised writing at the paragraph level, meaning they seldom had to write a complete essay.

Table 3: Student experience in writing.

\begin{tabular}{|c|c|}
\hline Student experience in writing & Percentage \\
\hline Writing experience was very limited & $34 \%$ \\
\hline Writing was only to prepare for exams. & $52 \%$ \\
\hline Training was largely paragraph writing rather than essay writing. & $31 \%$ \\
\hline
\end{tabular}

These findings add empirical evidence to research by Zhao (2016) and Xie (2015) who reported that writing skills are not emphasised in the curricula for secondary schools in China. As a consequence, writing skills are normally not taught in secondary schools until Senior III, the year students sit for the NMET. Before this year, writing practice is fundamentally at the sentence level, i.e. combining simple sentences to make complex sentences and translating sentences from Chinese into English (Qi 2007).

\section{Strategies for achieving high scores on the NMET}

When asked about strategies adopted for their high writing scores on the NMET, most participants attributed their success to the following four factors: maintaining clear and neat handwriting (68\%), using beautiful structures and shining phrases (51\%), inserting sentence connectors (69\%) and extending the length and complexity of their sentences in writing $(67 \%)$. 
Table 4: Writing strategies recommended by teachers.

\begin{tabular}{|c|c|}
\hline Strategies & Percentage \\
\hline Maintaining tidiness of scripts & $68 \%$ \\
\hline Writing long and complex sentences and advanced words & $67 \%$ \\
\hline Using connectors & $69 \%$ \\
\hline Using beautiful structures and shining phrases & $51 \%$ \\
\hline
\end{tabular}

These strategies, according to the discussants at the focus-group interview, were recommended by their teachers who received information from "insiders" of the NMET, i.e. those who had participated in the marking of NMET writing scripts. This result accords with a number of studies (e.g. Paltridge 2007, Xie 2015) which have documented some of the "insider" views. In accordance with these views, both explicit and implicit assessment criteria are adopted by the NMET markers. One of the most surprising implicit criteria is candidates' ability to maintain a desirable appearance of their writing scripts, which includes clear and neat handwriting. This "insider" view was confirmed by the discussants of the current study. Of their comments, one was most illuminating. The comment was a quote from the participant's secondary school English teacher: "You will receive at least 21 marks (out of 25) if your handwriting is clear and tidy and you have covered the main points required by the writing prompt". This remark explains why almost $70 \%$ of the subjects believed that their tidy and neat handwriting was a key factor for their high scores on the writing task of the NMET.

The other three strategies reported by the subjects were inserting "beautiful structures" (51\%), writing complex sentences and difficult words (67\%), and using a variety of sentence connectors, such as however, moreover, besides, to achieve cohesion and coherence in their writing (69\%). These three strategies, according to the discussants at the focus-group interviews, were also based on views of the NMET insiders and were very much recommended by their teachers.

The popularity of these writing strategies has contributed to the three major problems in the writing of Chinese mainland learners: use of unnecessarily difficult words and overly complex sentences, overuse and misuse of sentence connectors, and "flowery prose" (Singh \& Fu 2008: 121). The first was documented in Zhao (2009: 24) who reported that many learners "deliberately employed complex sentences and low-frequency lexis in their NMET compositions". Xie (2015) also discussed how some test-takers deployed sophisticated words and complex sentences to manage rater impressions. The second, overuse and misuse of sentence connectors, was also well-documented in the literature (see Gao 2016, Leedham \& Cai 2013, Lei 2012) and can be exhibited in a paragraph written by one of the participants of the current study.

Firstly, as we all know, economic development is based on the environment. If the lands are all deserts and there is no water, we will not be able to construct a beautiful city. Also, assume that we can construct a beautiful city, the environment is not good enough for people to live in. So, environmental protection plays an important part in the modern society.

The third, flowery prose, is closely related to learners' deployment of "beautiful structures" and "shining phrases" in their writing. These structures and phrases are highly regarded by students, teachers and authors of NMET preparation book in mainland China. Wang's (2013) book, for example, lists 209 proverbs and clichés, and 43 famous quotes and proverbs at the end of the book (pp. 296-309). These items were divided into categories according to themes in the book, but there was no explanation as to how to use them in context and, in particular, what types of writing genres the different proverbs/clichés/quotes might best be used in. This is possibly because many people in China believe that these structures and phrases are a "panacea" (You, 2010: 154) and therefore can be employed in any genre of writing. After all, "it is these beautiful and native-sounding sentences that will make your writing stand out". This "panacea" has contributed to the production of "flowery prose".

Apart from NMET preparation books, learners in China can also learn "beautiful structures" and "shining phrases" from sample essays and essay templates provided by their teachers. The template below represents a typical example in this regard: 
Nowadays, there is a widespread concern over the issue that there are both advantages and disadvantages in (essay topic). In fact, (first advantage). And secondly
Just as a popular saying goes, "Every coin has two sides", (the main issue). Generally there are several positive aspects as follows. First (second advantage).

exception, and in another word, it still has negative aspects. To begin with, (first disadvantage). In addition, ___ (second disadvantage).

To sum up, we should try to bring the advantages of (the main issue) into full play and reduce the disadvantages to the minimum at the same time. In that case, we will definitely make a better use of the (the main issue).

This template for argumentative essays was from a participant of the current study who received it from his secondary school English teacher. The italicised parts (in brackets) were in Chinese in the original template and were translated into English by the author for the purpose of the present study. There are 110 words in this template and the total word limit for NMET essays is around 100.This means if this template is adapted by students for the NMET, they will only need to compose very few sentences by themselves. More importantly, the template contains "beautiful structures" and "shining phrases", such as, "it is widely believed that", "every coin has two sides" and "reduce ... to a minimum" and other elements required for top-grade compositions on the NMET, such as advanced lexis, complex sentence structures, and sentence connectors. It is not difficult to envisage that a candidate who has memorised this template will obtain a high score because all $\mathrm{s} /$ he needs to do is to translate the italicised parts into English and some of the translations (e.g. main issue of the topic) may have been given in the test prompts already.

This by and large explains why many participants in the current study memorised exemplary essays (58\%) and essay templates (79\%) before the NMET (see Table 5). Memorising these texts and templates forms a crucial part of the intensive training for the NMET. Because of the availability of these templates and exemplary essays, some teachers even never provide specific feedback on students' compositions because teachers can simply ask students to compare their compositions with the provided exemplary texts so as to identify areas they need to improve (see Paltridge 2007, Yu 2012, Zhao 2009).

Table 5: Extensive training for the NMET.

\begin{tabular}{|c|c|}
\hline Preparatory tasks & Percentage \\
\hline Reciting exemplary essays & $58 \%$ \\
\hline Memorising essay templates & $79 \%$ \\
\hline Vocabulary and grammar training & $78 \%$ \\
\hline
\end{tabular}

Another important aspect of the extensive training for the NMET is grammar and vocabulary. Most participants for the study (78\%) received such training. This practice, as reported by the discussants in the focus-group interviews, was partially attributed to the centrality of language accuracy, including the use of sophisticated lexis and complex sentence structures, in the marking of NMET writing scripts. It is not difficult to understand the importance that most respondents attached to vocabulary and grammar because these two facets of knowledge have been regarded as the foundations of a language (Barani \& Seyyedrezaie 2013, Delmonte 2008). Lexical knowledge is even considered as a "precondition" for other language skills (Roche \& Harrington 2013: 2). This belief is apparently shared by many Chinese learners who believe that "learning English is largely a matter of learning new words" (Jin \& Cortazzi 2006: 11). One learner metaphorically describes this learning belief: "Words are the bricks a building is made up of. Without bricks, where will the building be?" (Gan, Humphreys \& Hamp-Lyons 2004: 234). So, to learners like this one, learning English is a matter of collecting bricks (i.e. new words).

The problem of this learner belief is that from knowing the meaning of a word to being able to use it appropriately in contexts is an arduous and onerous journey for most EFL (English as a foreign language) learners. These learners need to be guided by teachers to use words they have learnt to write and speak in English because learners' productive language skills can improve only from their efforts in language production (Schmitt 2014). However, this much needed guidance seems absent from the teaching of 
English in China. This absence is evident in Qi's (2004) study in which a teacher vividly describes how she prepares her students for the NMET:

The most important training is in vocabulary. Every year I print the NMET vocabulary list for my students and ask them to memorise every single word on the list. I facilitate their memorisation by conducting frequent quizzes in class. At each quiz, I give students 100 English words and ask them to write the corresponding Chinese meaning of these words and then vice versa, i.e. give students 100 Chinese words and ask them to write down the corresponding English meaning. The quizzes take place every week.

*Translation of the author. Original text in Chinese (See Note 2)

\section{Writing problems encountered by mainland students in Hong Kong - a snapshot}

After undergoing such training, many students might have gained strategies for obtaining high scores at the NMET. However, these strategies backfire when the learners encounter the demands of academic writing in their overseas studies (Edwards, Ran, \& Li 2007). This explains why many mainland students in Hong Kong universities experience serious challenges. A number of interviewees for this study reported that they found it difficult to manage their studies in the university, ranging from understanding lecture content, comprehending technical reading, to speaking and writing effectively in English. Consequently, many of them could not perform satisfactorily in their assessments. One of the examples was Kathy (a pseudonym).

Kathy was from Beijing. She attained a very high grade on the NMET (142 out of 150), particularly in writing (27 out of 30, see Note 3). Kathy believed the grades a learner received from high-stakes English tests were the most reliable indicators of her English proficiency. In her view, two factors were essential for obtaining top grades on such tests: memorising as many low-frequency words as possible and composing long complex sentences in essay writing. To achieve the vocabulary goal, she memorised word lists and set-phrases from her textbooks as well as from preparation books for TOEFL (Test of English as Foreign Language, one of the most widely accepted university admissions test) and even GRE (Graduate Record Examinations, a standardised worldwide admissions test for graduate studies). To accomplish her mission of using long and complex sentences in writing, she diligently worked on grammar and used many sentence-connectors (mainly conjunctions) in her essays.

Kathy's strategies seemed to have worked well considering her outstanding performance on the NMET. However, after entering the university, she suffered a series of setbacks, of which the most frustrating one was the low grades she received for her essays. Comments on her essays related to the low grades were mainly twofold:

1. lack of cohesion, coherence and clarity in her content development;

2. use of overly long sentences and unnecessarily difficult words

This was a major setback for Kathy. In her secondary school, she seldom needed to ponder over the content development of her essays because of the essay templates she memorised. More importantly she was taught to employ long sentences and difficult words in order to achieve a high mark on the NMET. To her, these were crucial skills for effective writing. However, it was these very skills that had become a major barrier to her success in writing academic essays at university. Kathy was confused, frustrated and even depressed. She was advised to change her dense and ponderous writing style, but she found it difficult to make such a change. The main reason, she claimed, was that she did not know how to compose simple sentences anymore.

\section{Conclusion and implications}

This study has provided both qualitative and quantitative data about the impacts of the writing component of the NMET on students' writing skills in mainland China. The results of the study suggest that instead of testing learners' writing skills as it intends to, this high-stakes test mainly measures candidates' test-taking skills and even memorisation abilities. One impact of this problem is many learners' misplaced motivation for writing, i.e. rather than write for communication purposes, these students learn to write for passing examinations. A more serious consequence is that the NMET has 
shaped many learners' views of what count as good writing. To these learners, an effective essay is a flowery prose that contains many overly long and complex sentences, unnecessarily difficult words, and beautiful structures and shining phrases (Qi 2007, Singh \& Fu 2008). This misconception could hinder their long-term development in writing academic texts.

The results of the study have also provided empirical data for Qi's (2007) observation that the writing component in the NMET cannot discriminate between different candidates' writing proficiency. Since this test is ineffective in testing students' writing skills, are form of the NMET is urgently needed in China, in particular in changing the writing component of the test, its test design as well as its marking criteria.

\section{Notes}

1. 学生仅用基本的词汇和基本的句型, 不能体现出较强的语言运用能力。即使表达无语法错 误, 也不能得高分。相反有些错误, 目的在有意识地使用复杂结构或较高级词汇, 仍属于较高 当初。

2. 最重要的是背单词。我每年都把NMET考试大纲的单词印发给学生, 要他们背, 然后测试。我给 出100个英语词, 要他们写出汉语意思, 再给100个汉语词, 要他们写出英语词。每周考。

3. The total score given to the writing section of the NMET varies, ranging from 25 to 35 , in different provinces/capital-cities that set their own NMET papers. The scores allocated to this section depends on the decision of each local government.

\section{References}

Barani, S. \& Seyyedrezaie, S. H. (2013). Language Learning and Vocabulary: (A review). International Journal of Basic Sciences \& Applied Research, 2 (1), 87-90.

Cheng, L. (2008). The key to success: English language testing in China. Language Testing, 25 (1), 15-37. https://doi.org/10.1177/0265532207083743.

Cheng, L. \& Curtis, A. (2010). The Impact of English Language Assessment and the Chinese Learner in China and Beyond. In L. Cheng \& A. Curtis (Eds.), English Language Assessment and the Chinese Learner (pp. 268-273). New York \& London: Routledge.

Cheng, L. \& Qi, L. (2006). Description and Examination of the National Matriculation English Test. Language Assessment Quarterly, 3 (1), 53-70. https://doi.org/10.1207/s15434311laq0301_4.

Delmonte, R. (2008). Computational Linguistic Text Processing: Lexicon, Grammar, Parsing and Anaphora Resolution. New York: Nova Science Publishers.

Edwards, V., Ran, A. \& Li, D. (2007). Uneven playing field or falling standards?: Chinese students' competence in English. Race Ethnicity and Education, 10 (4), 387-400. https://doi.org/10.1080/13613320701658431

Fox, J. \& Curtis, A. (2010). International English Language Testing System. In L. Cheng \& A. Curtis (Eds.), English Language Assessment and the Chinese Learner (pp. 112-120). New York \& London: Routledge.

Gan, Z., Humphreys, G. \& Hamp-Lyons, L. (2004). Understanding Successful and Unsuccessful EFL Students in Chinese Universities. The Modern Language Journal, 88 (2), 229-244. https://doi.org/10.1111/j.00267902.2004.00227.x

Gao, X. (2016). A cross-disciplinary corpus-based study on English and Chinese native speakers' use of linking adverbials in academic writing. Journal of English for Academic Purposes, 24, 14-28. https://doi.org/10.1016/j.jeap.2016.08.002.

Gu, P. Y. (2014). The unbearable lightness of the curriculum: What drives the assessment practices of a teacher of English as a Foreign Language in a Chinese secondary school? Assessment in Education: Principles, Policy \& Practice, 21 (3), 286-305. https://doi.org/10.1080/0969594X.2013.836076.

Hu, G. (2003). English Language Teaching in China: Regional Differences and Contributing Factors. Journal of Multilingual and Multicultural Development, 24 (4), 290-318. https://doi.org/10.1080/01434630308666503.

Jin, L. \& Cortazzi, M. (2006). Changing Practices in Chinese Cultures of Learning. Language, Culture and Curriculum, 19 (1), 5-20. https://doi.org/10.1080/07908310608668751.

Leedham, M. \& Cai, G. (2013). Besides ... on the other hand: Using a corpus approach to explore the influence of teaching materials on Chinese students' use of linking adverbials. Journal of Second Language Writing, 22 (4), 374-389. https://doi.org/10.1016/j.jslw.2013.07.002. 
Lei, L. (2012). Linking adverbials in academic writing on applied linguistics by Chinese doctoral students. Journal of English for Academic Purposes, 11 (3), 267-275. https://doi.org/10.1016/j.jeap.2012.05.003.

Mei, Y. \& Cheng, L. (2014). Scoring Fairness in Large-Scale High-Stakes English Language Testing: An Examination of the National Matriculation English Test. In D. Coniam (Ed.), English Language Education and Assessment: Recent Developments in Hong Kong and the Chinese Mainland (pp. 171-187). Singapore: Springer Singapore.

Paltridge, B. (2007). Beyond the text: A textography of Chinese College English writing. University of Sydney Papers in TESOL, 2 (2), 149-165.

Qi, L. (2004). Washback Effects of the NMET. Teaching and Researching in Foreign Language Studies, 36 (5), $357-$ 363.

Qi, L. (2007). Is testing an efficient agent for pedagogical change? Examining the intended washback of the writing task in a high-stakes English test in China. Assessment in Education: Principles, Policy \& Practice, 14 (1), $51-74$. https://doi.org/10.1080/09695940701272856.

Qian, D. D. \& Cumming, A. (2017). Researching English Language Assessment in China: Focusing on High-Stakes Testing. Language Assessment Quarterly, 14 (2), 97-100. https://doi.org/10.1080/15434303.2017.1295969.

Roche, T. \& Harrington, M. (2013). Recognition vocabulary knowledge as a predictor of academic performance in an English as a foreign language setting. Language Testing in Asia, 3 (12), 1-13.

Shaw, S. \& Falvey, P. (2008). The IELTS writing assessment revision project: Towards a revised rating scale. Cambridge ESOL Research Reports, 23, 7-12.

Shaw, S. D. \& Weir, C. J. (2007). Examining Writing: Research and Practice in Assessing Second Language Writing (Studies in Language Testing 26). English Teaching as a Second or Foreign Language, 11 (4), 1-3. https://www.tesl-ej.org/pdf/ej44/r3.pdf.

Schmitt, N. (2014). Size and Depth of Vocabulary Knowledge: What the Research Shows. Language Learning, 64 (4), 913-951. https://doi.org/10.1111/lang.12077.

Singh, M. \& Fu, D. (2008). Flowery Inductive Rhetoric Meets Creative Deductive Arguments Becoming Transnational Researcher. International Journal of Asia Pacific Studies, 4 (1), 121-137.

Song, X. (2016). Fairness in Educational Assessment in China: Historical Practices and Contemporary Challenges. In S. Scott, D. E. Scott \& C.F. Webber (Eds.), Assessment in Education: Implications for Leadership (pp. 67-89). Cham: Springer Publishing.

Wang, Y. F. (2013). Full-mark Compositions on the NMET. Beijing: Beijing Education Press.

Wu, Q. (2008). Washback of the Writing Part in NMET. Foreign Language Studies, 28, 565-566.

Xie, Q. (2015). “I must impress the raters!" An investigation of Chinese test-takers' strategies to manage rater impressions. Assessing Writing, 25, 22-37.

$\mathrm{Xu}, \mathrm{Y}$. \& Wu, Z. (2012). Test-taking strategies for a high-stakes writing test: An exploratory study of $12 \mathrm{Chinese} \mathrm{EFL}$ learners. Assessing Writing, 17 (3), 174-190.

You, X. (2004). "The choice made from no choice": English writing instruction in a Chinese University. Journal of Second Language Writing, 13 (2), 97-110. https://doi.org/10.1016/j.jslw.2003.11.001.

You, X. (2010). Writing in the Devil's Tongue: A History of English Composition in China. Carbondale: Southern Illinois University Press. Retrieved from https://muse.jhu.edu/book/1614.

Yu, X. (2012). Text Memorisation in Chinese Foreign Language Education. Bern: Peter Lang AG.https://eric.ed.gov/?id=ED531322.

Zhao, J. (2009). Error analysis on students' English writing in senior high school and pedagogical suggestions. Northeast Formal University, Changchun, China.

Zhao, J. (2016). The reform of the National Matriculation English Test and its impact on the future of English in China: Will English lose its predominance in the Chinese foreign language landscape? English Today, 32 (2), 38 44. https://doi.org/10.1017/S0266078415000681. 